\title{
Recent advances in diagnosis and treatment of atypical haemolytic uraemic syndrome Paula HB Bolton-Maggs
}

Address: Department of Clinical Haematology, Manchester Royal Infirmary, Oxford Road, Manchester, M13 9WL, UK

Email: paula.bolton-maggs@manchester.ac.uk

FI000 Medicine Reports 2010, 2:73 (doi:10.3410/M2-73)

This is an open-access article distributed under the terms of the Creative Commons Attribution-NonCommercial License (http://creativecommons.org/licenses/by-nc/3.0/legalcode), which permits unrestricted use, distribution, and reproduction in any medium, for non-commercial purposes provided the original work is properly cited. You may not use this work for commercial purposes.

The electronic version of this article is the complete one and can be found at: http://fl000.com/reports/medicine/content/2/73

\begin{abstract}
New understanding of the underlying pathology of the thrombotic microangiopathies has resulted in guidelines for the investigation and management of atypical haemolytic uraemic syndrome in children and adults and the prospect of new therapies, which are in clinical trial. Patients should be investigated for defects in complement pathways and a trial of plasma exchange is indicated.
\end{abstract}

\section{Introduction and context}

Atypical haemolytic uraemic syndrome (aHUS) belongs to a group of thrombotic microangiopathies in which the kidney is the primary target. It is characterised by microangiopathic haemolytic anaemia with thrombocytopenia and renal failure and is distinguished from classical diarrhoea-associated HUS typically occurring in childhood (caused by Shiga-toxin-producing bacteria and with a good prognosis; $>90 \%$ children recover normal renal function with supportive therapy) and characterized by its chronic and relapsing course. The presentation of aHUS may overlap with classic thrombotic thrombocytopenic purpura (TTP), a disorder where the combination of microangiopathic haemolytic anaemia and thrombocytopenia is often associated with neurological symptoms but usually less severe renal dysfunction. TTP is most frequently caused by a deficiency of the von Willebrand cleaving protease ADAMTS13 (a disintegrin and metalloproteinase with thrombospondin motifs-13), commonly as a result of autoantibody production and rarely as a result of congenital deficiency of this enzyme. The evidencebased treatment for TTP is plasma exchange (PEX) [1]. aHUS is a rare (about two cases per million people per year in the UK) and serious condition (both inherited and acquired forms) prone to relapses, with both a high mortality and substantial risk of end-stage renal disease.

\section{Recent advances}

aHUS is triggered by dysregulation of the alternative complement activation pathway, an important defence mechanism for the recognition and elimination of pathogens [2]. Several different defects have been identified overall in about $50 \%$ of cases $[3,4]$. The alternative pathway is in a state of constant autoactivation ('tickover') (Figure 1) and therefore requires continuous active control. A succession of proteolytic steps involving complement component 3 (C3) and complement factors B and D results in an amplification loop that enhances complement activation. Ultimately, C5 activation results in generation of the membrane attack complex with resultant cell lysis. Activation is controlled by inhibitory proteins, factor $\mathrm{H}$ and membrane-bound cofactor protein (MCP, now known as $\mathrm{CD} 46)$. Factor I is a serine protease that inactivates C3b and $\mathrm{C} 4 \mathrm{~b}$ with cofactors factor $\mathrm{H}$ and $\mathrm{C} 4 \mathrm{~b}$ binding protein. Abnormalities have been described in the genes for most components (factor $\mathrm{H}$ [in 30\% of patients], CD46 [in $10-15 \%$ of patients], factor I [in $10 \%$ of patients], factor B, C3, factor H-related proteins 1-5, and thrombomodulin) [3-6], leading to the pathology and outlook of this disease. While most mutations result in defective function of regulatory proteins, gain-of-function mutations can result in overactivation of the pathway ('super factor B') [7,8]. Some young patients (about 10\%) have autoantibodies against factor $\mathrm{H}$, particularly in a 
Figure I. Complement activation pathways

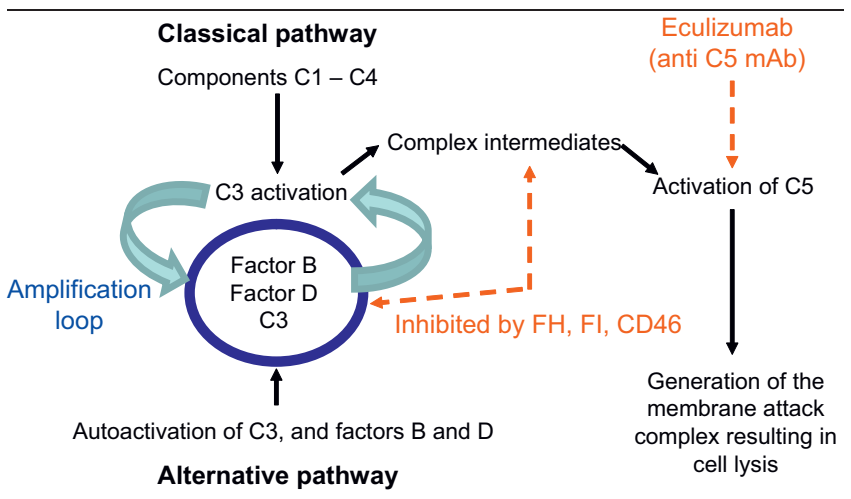

All complement pathways converge in the production of complement component 5 (C5) and the membrane attack complex. Inhibitors are shown in red and include factor $\mathrm{H}(\mathrm{FH})$, factor I (FI), and CD46, which inhibit the alternative pathway. mAb, monoclonal antibody.

setting of predisposing mutations in other complement components (e.g., the CFHR1 [complement factor $\mathrm{H}$ related 1] gene [9]). Some patients with aHUS have ADAMTS13 deficiency. These findings have generated new guidance for diagnosis (to recognise these different mechanisms) and management (particularly to standardise and audit outcome in this rare disease), and also new possibilities for treatment using inhibitors of the alternative pathway.

\section{Implications for clinical practice}

The optimal primary management of aHUS remains unclear. The differentiation of diarrhoeal HUS from aHUS in childhood may be difficult [5]. Because aHUS is severe with high mortality, and difficult to distinguish from TTP, PEX should be started immediately if aHUS is suspected (based on expert opinion rather than clinical trials) $[5,6,10,11]$. A consistent approach to treatment may result from application of guidelines, but it is essential that outcome data are collected from these rare cases into a registry so that in future there is clear evidence for treatment. Prior to infusion of plasma, blood samples should be taken for assessment of complement components ( $\mathrm{C} 3$, factors $\mathrm{H}$ and $\mathrm{I}$, antifactor $\mathrm{H}$ antibodies, and CD46) and for gene mutation analysis (factor $\mathrm{H}$, factor I, CD46, factor B, and C3) suitable laboratories are listed in the guidelines $[5,6]$. The results do not influence immediate management, but enable some prediction to be made about the indications and likely success of renal transplantation (e.g., poor outcome predicted in those with mutations in the genes encoding complement factors $\mathrm{H}$ or I [CFH or CFI]). PEX daily for 5 days then tailing off over 4 more weeks is recommended [6] but can be tailored to individual requirements [5,6]. Patients with isolated
CD46 dysfunction (membrane bound) are unlikely to respond to PEX (but have a better long-term outcome) [5], in contrast to those with autoantibodies to factor $\mathrm{H}$ who respond well to PEX and immunosuppression [2]. Patients with autoantibody-induced HUS who require renal transplantation need immunosuppressive therapy prior to and during transplantation.

New therapies are on the horizon. A monoclonal antibody targeted against C5, eculizumab, has been beneficial in some cases of aHUS [12,13]. A clinical trial is underway with a target recruitment of 15 patients and is expected to complete later this year [14]. This is an exciting development that may offer a more beneficial therapy in this serious disease. Other therapeutic strategies under investigation include factor $\mathrm{H}$ concentrate, and synthetic complement regulators.

\section{Abbreviations}

ADAMTS13, a disintegrin and metalloproteinase with thrombospondin motifs-13; aHUS, atypical haemolytic uraemic syndrome; PEX, plasma exchange; TTP, thrombotic thrombocytopenic purpura.

\section{Competing interests}

The author declares that she has no competing interests.

\section{References}

I. Allford SL, Hunt BJ, Rose P, Machin SJ: Guidelines on the diagnosis and management of the thrombotic microangiopathic haemolytic anaemias. Br J Haematol 2003, I 20:556-73.

2. Skerka C, Jozsi M, Zipfel PF, Dragon-Durey MA, Fremeaux-Bacchi V: Autoantibodies in haemolytic uraemic syndrome (HUS). Thromb Haemost 2009, 10 I:227-32.

3. Kavanagh D, Goodship T: Genetics and complement in atypical HUS. Pediatr Nephrol 2010, [Epub ahead of print].

4. Sanchez-Corral P, Melgosa M: Advances in understanding the aetiology of atypical Haemolytic Uraemic Syndrome. $\mathrm{Br} J$ Haematol 2010, 150:529-42.

5. Ariceta G, Besbas N, Johnson S, Karpman D, Landau D, Licht C, Loirat C, Pecoraro C, Taylor CM, Van de Kar N, Vandewalle J, Zimmerhackl LB; European Paediatric Study Group for HUS: Guideline for the investigation and initial therapy of diarrheanegative hemolytic uremic syndrome. Pediatr Nephrol 2009, 24:687-96.

6. Taylor CM, Machin S, Wigmore SJ, Goodship TH: Clinical practice guidelines for the management of atypical haemolytic uraemic syndrome in the United Kingdom. $\mathrm{Br} J$ Haematol 2010, I48:37-47.

FI000 Factor 6.0 Must Read Evaluated by Paula Bolton-Maggs 09 Feb 2010

7. Roumenina LT, Jablonski M, Hue C, Blouin J, Dimitrov JD, DragonDurey MA, Cayla M, Fridman WH, Macher MA, Ribes D, Moulonguet L, Rostaing L, Satchell SC, Mathieson PW, Sautes-Fridman C, Loirat C, Regnier CH, Halbwachs-Mecarelli L, Fremeaux-Bacchi V: Hyperfunctional C3 convertase leads to complement deposition on endothelial cells and contributes to atypical hemolytic uremic syndrome. Blood 2009, I | 4:2837-45.

8. Conway EM: Super factor B-gets atypical HUS. Blood 2009, I | 4:2572-4. 
9. Abarrategui-Garrido C, Martinez-Barricarte R, Lopez-Trascasa M, de Cordoba SR, Sanchez-Corral P: Characterization of complement factor H-related (CFHR) proteins in plasma reveals novel genetic variations of CFHRI associated with atypical hemolytic uremic syndrome. Blood 2009, I | 4:426 I-71.

FI000 Factor 3.0 Recommended

Evaluated by Neil Sheerin 25 Nov 2009

10. Michael M, Elliott EJ, Ridley GF, Hodson EM, Craig JC: Interventions for haemolytic uraemic syndrome and thrombotic thrombocytopenic purpura. Cochrane Database Syst Rev 2009, I:CD003595.

II. Szczepiorkowski ZM, Bandarenko N, Kim HC, Linenberger ML, Marques MB, Sarode R, Schwartz J, Shaz BH, Weinstein R, Wirk A, Winters JL; American Society for Apheresis; Apheresis Applications Committee of the American Society for Apheresis: Guidelines on the use of therapeutic apheresis in clinical practice: evidencebased approach from the Apheresis Applications Committee of the American Society for Apheresis. J Clin Apher 2007, 22:106-75.

12. Gruppo RA, Rother RP: Eculizumab for congenital atypical hemolytic-uremic syndrome. N Engl J Med 2009, 360:544-6.

13. Nürnberger J, Philipp T, Witzke O, Opazo Saez A, Vester U, Baba HA, Kribben A, Zimmerhackl LB, Janecke AR, Nagel M, Kirschfink M: Eculizumab for atypical hemolytic-uremic syndrome. $N$ Engl J Med 2009, 360:542-4.

14. Open Label Controlled Trial of Eculizumab in Adult Patients With Plasma Therapy-sensitive Atypical Hemolytic Uremic Syndrome (aHUS). [http://clinicaltrials.gov/ct2/show/record/ NCT008385I3] 